\title{
One Conference, Three Proceedings - Which Papers Should I Submit and How? A Publication Strategy for Young Scientists Regarding the GMDS Annual Conference and Beyond (Editorial)
}

\author{
Björn SCHREIWEIS ${ }^{\mathrm{a}, \mathrm{c}, 1}$, Ann-Kristin KOCK-SCHOPPENHAUER ${ }^{\mathrm{b}, \mathrm{c}}$ \\ anstitute for Medical Informatics and Statistics, Kiel University and University \\ Hospital Schleswig-Holstein, Kiel, Germany \\ ${ }^{b} I T$ Center of Clinical Research, Universität zu Lübeck, Lübeck, Germany \\ ${ }^{c}$ German Association for Medical Informatics, Biometry and Epidemiology, Cologne, \\ Germany

\begin{abstract}
The primary intention of any scientific work is to share the gained knowledge and to contribute to the knowledge and progress in the scientific domain. The wide range of journals and conferences, each with specific submission requirements, can be difficult to navigate, especially for young scientists without extensive experience. But a suitable publication strategy can be helpful, especially at the beginning of a scientific career. Using the annual conference of the German Association for Medical Informatics, Biometry and Epidemiology (GMDS) e.V. as an example, this editorial highlights fundamental differences, advantages and disadvantages, as well as assistance in selecting the right form of submission.
\end{abstract}

Keywords. GMDS, Abstract, Full Paper, MIBE, Publication Strategy

\section{Introduction}

The 'German Association for Medical Informatics, Biometry and Epidemiology (GMDS) e.V.' is an independent scientific medical society whose primary field of activity is medical informatics, medical biometry, epidemiology, medical bioinformatics, and systems biology, including medical documentation in theory and practical application, and research and education. The GMDS is the official national member society within the international medical informatics associations European Federation for Medical Informatics (EFMI) and IMIA - International Medical Informatics Association and closely cooperates with related German scientific societies like Deutsche Gesellschaft für Epidemiologie e.V. (DGEpi), Deutscher Verband

\footnotetext{
${ }^{1}$ Corresponding Author: Prof. Dr. Björn Schreiweis, Institute for Medical Informatics and Statistics, Kiel University and University Hospital Schleswig-Holstein, Arnold-Heller-Straße 3, 24105 Kiel E-mail: bjoern.schreiweis@uksh.de.
} 
Medizinischer Dokumentare e.V. (DVMD) or TMF - Technology, Methods, and Infrastructure for Networked Medical Research e.V.

While the origins of the GMDS can be traced back to 1951, it finally constituted itself as a society in 1955. It is thus the oldest professional society in Europe in the field of medical documentation, informatics, and statistics [1]. In 1956, the GMDS started to organize its annual conferences for members and interested parties. In 2020, the 65th GMDS annual conference was celebrated unfortunately as an online event due to the ongoing COVID-19 pandemic. The GMDS has seen steady growth in membership and now welcomes over 2000 members. The annual conferences attract national and international attention with usually about 700 attendees and 4 days of presentations and sessions. International keynote speakers are invited to the conferences and contribute relevant information to the GMDS society [2]. It was common practice to submit abstracts of 500 words for the GMDS annual conference, which were presented as a paper or poster and published via the German Medical Science (eGMS) [3], a portal for online journals, meetings and research reports. In addition, selected papers were invited for a full paper submission e.g. to the Journal of Methods of Information in Medicine.

The GMDS is always trying to keep its members' attractiveness and motivation, which inevitably results in changes for the annual meetings. Due to external requirements, the publication strategy is increasingly directed towards listed publications and favors these. Following this trend, in 2017, the 62nd Annual Meeting in Oldenburg (Germany) offered the possibility to submit full papers for the first time in addition to abstracts. As of now, submissions for three different proceedings are accepted: Series 'German Medical Data Sciences' in Studies in Health Technolology and Informatics [2], GMS Medizinische Informatik, Biometrie und Epidemiologie (MIBE) and German Medical Sciences Proceedings (eGMS). All contributions are open access, but each of these proceedings have different formats, instructions for authors, and reputation within the disciplines.

New opportunities, however, always present new challenges: the variety of publication options, their smooth transition between conferences and journal articles does not necessarily simplify the decision of which topic should be published in which format, especially for young scientists. Based on the subjective experience of the authors and using the example of the annual meeting of the German Society for Medical Informatics, Biometry and Epidemiology (GMDS) e.V., this editorial aims to highlight the advantages and disadvantages of different publication types, to increase the appreciation of conference contributions and to provide guidance for submission decisions.

\section{Why submitting to a conference?}

The ultimate objective of any academic work is to publish the scientific output and share the knowledge gained. In this process, careful consideration must be given beforehand as to which form of publication, e.g. journal publication or conference proceeding one chooses. In contrast to journal publication, publications at conferences have the advantage that they allow the authors to present their work to live audience. In a lecture or during the poster presentation, a direct exchange with colleagues and experts in the domain can take place. But, it is not only the presentation that provides the opportunity for exchange. Due to the networking possibilities new project partners or cooperation's can be established and authors receive first-hand feedback. Conferences offer the 
opportunity to share concentrated knowledge, establish contact with experts, gain new insights and broaden individual perspectives.

Journal and conference publications differ in the submission and review processes: Usually there are submission deadlines for conferences. In contrast to journals, where several issues are published over the year and a continuous review and publication process is established, conferences take place at a specific time and in preparation for this event submissions are received and reviewed with previously announced deadlines. With these deadlines the publication of the manuscripts can be well planned and sorted. The overall period between submission and publication is usually shorter compared to journal publication and marked by deadlines. These deadlines can help scientists finish a submission and not delay completion.

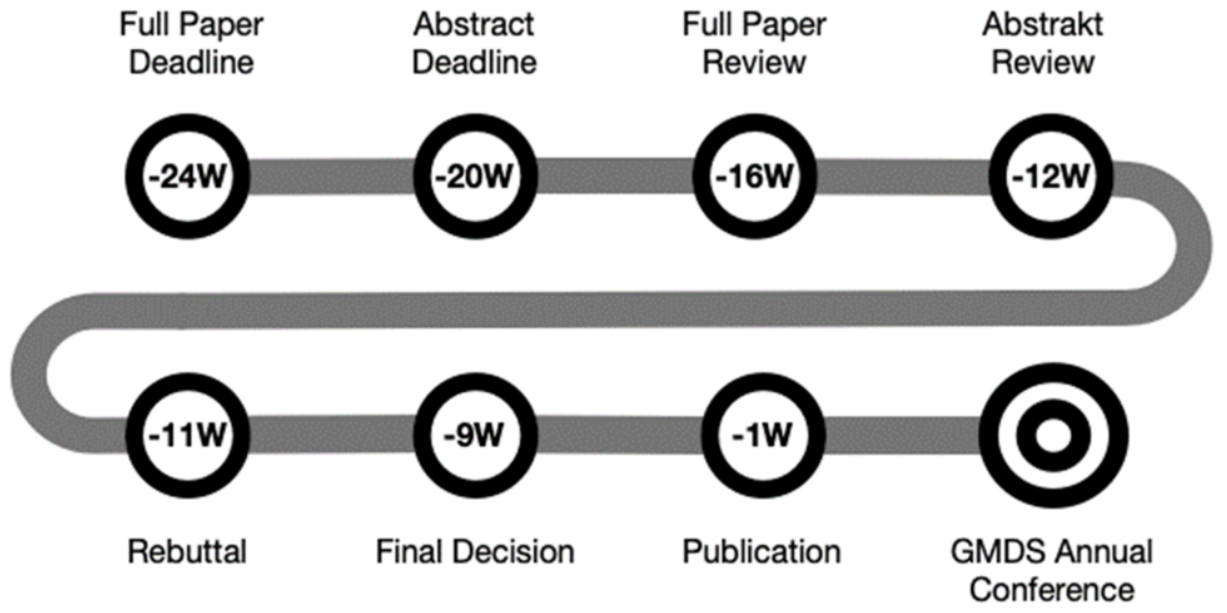

Figure 1 Timeline for publication steps according to the $66^{\text {th }}$ GMDS annual conference in 2021.

The time from submission to publication for journals depends on the submitted paper, the journal itself and the reviewers and can vary between a few months up to over a year. The publication history which is obligatory on each journal paper helps to estimate the for authors considering to submit a manuscript to that journal.

In general, for some disciplines, the hurdles and inhibition for papers at conferences is perceived to be relatively lower than for journal articles. This is mainly because, the number of pages is usually limited, and conference papers are more suitable for contributions that are not quite as extensive in terms of content, such as bachelor's or master's theses or preliminary publications of projects for which a journal paper is intended. Conferences are often the first step towards publishing research results, as they are recommended by the supervisors and there are various offers for young scientists, such as the best paper award at the GMDS annual meeting or dedicated sessions for young scientists. But from a personal perspective it is also important to take the plunge and submit results to journals. The first impression of young scientists that journal publications are unattainable is just not true, but on the other hand one should not be discouraged by first rejections. 


\subsection{What can be submitted?}

Only unpublished 'original research' with new and unpublished findings will be accepted at the GMDS annual conference. In addition, the conference considers systematic reviews such as meta-analyses or scoping reviews as original work. Manuscripts for full papers are not previously published in print or electronic form and must not have been submitted to another conference, journal, or publisher for review/publication. Prior publication of an abstract, or presentation of results at another meeting is permitted, but this must be indicated at the time of submission and in the manuscript.

Abstracts include unpublished original work, but also previously published abstracts at other conferences like MedInfo or MIE, if they are marked accordingly can be submitted to present the work to another audience. Publication of a previously published GMDS abstract in a journal or a full paper may be possible depending on the guidelines and should be checked with the journal's instructions for authors before submitting the abstract. In addition, tutorials and workshops may be submitted to the annual meetings.

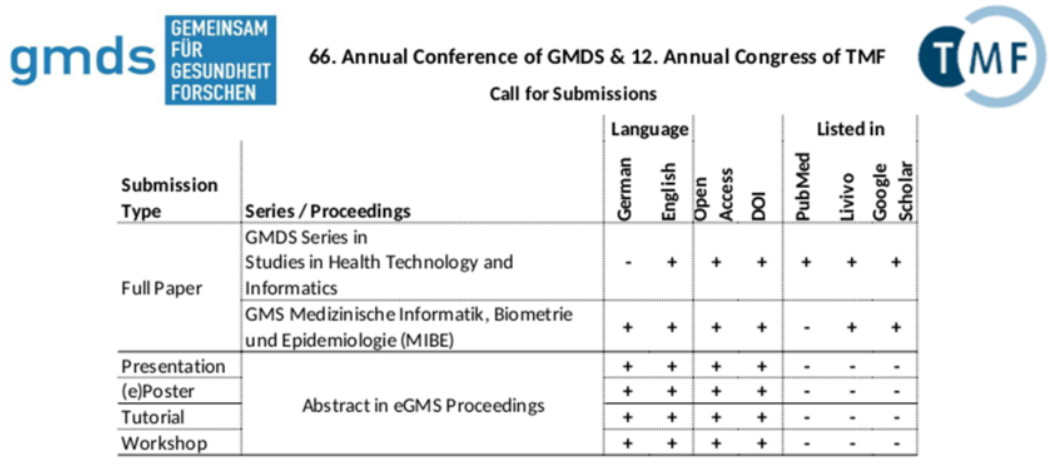

Figure 2 Overview of publication types and formats according to the $66^{\text {th }}$ GMDS annual conference.

\subsection{How are the different proceedings characterized?}

GMDS publishes all full papers and abstracts open access, which will be assigned a Document Object Identifier (DOI). Abstracts are published via eGMS. They must not exceed 500 words and include unpublished original papers, but also previously published abstracts. They can be written in either German or English and usually follow the same structure as full papers (see 2.3).

Full papers are published either in MIBE or as part of the series 'German Medical Data Sciences' in Studies in Health Technology and Informatics. The editorial board of MIBE pursues the aim to publish scientific activities with a major impact on German legislation, policy and routine practice in the peer-reviewed open access journal in German language. Offering publications in German can make a difference to the stakeholders' perception e.g. politicians, healthcare decision-makers, who are not necessarily familiar with publications in English or consider them less relevant for Germany. Contributions to MIBE can be written in English or German and must not exceed 25,000 characters [4]. Contributions for Studies in Health Technology and Informatics must be written in English and have an international interest with a maximum length of 8 pages following the IOS Press template. When preparing a contribution, the 
instructions for authors of the targeted proceedings have to be strictly followed and the templates provided have to be used.

The review process has two rounds: After the first review, the authors receive the reviewers' feedback. If the paper is generally acceptable, the acceptance is often accompanied by instructions for revision (minor or major revision), which are a prerequisite for final acceptance. The manuscript revised according to reviewer comments must be submitted via the online registry (for abstracts, Studies in Health Technology and Informatics and MIBE) and the MIBE review system with rebuttal letters and an additional version identifying the changes. The second stage of the review process is to assess whether the manuscript has been appropriately revised and can be accepted. For MIBE manuscripts, it is also decided whether the submission can be accepted to the special issue of the annual conference. If not, another round of peer review will be conducted according to the MIBE procedure. If successful, the manuscript may be published in a subsequent issue of MIBE.

\subsection{How to structure a submission}

Table 1. Most relevant reporting standards.

\begin{tabular}{|c|c|c|}
\hline Submission type & Reporting Standard & URL \\
\hline General & & $\begin{array}{l}\text { https://www.iospress.nl/wp- } \\
\text { content/uploads/2020/08/ECRC_Author } \\
\text { Instructions_and_tools_Word_2020.zip }\end{array}$ \\
\hline Randomized Controlled Trial & CONSORT [8] & $\begin{array}{l}\text { https://www.equator- } \\
\text { network.org/reporting- } \\
\text { guidelines/consort/ }\end{array}$ \\
\hline Observational Study & STROBE [9] & $\begin{array}{l}\text { https://www.equator- } \\
\text { network.org/reporting-guidelines/strobe/ }\end{array}$ \\
\hline Diagnostic and Prognostic Study & STARD [10] & $\begin{array}{l}\text { https://www.equator- } \\
\text { network.org/reporting-guidelines/stard/ }\end{array}$ \\
\hline Quality Improvement Study & SQUIRE [11] & $\begin{array}{l}\text { https://doi.org/10.1136/bmjqs-2015- } \\
004411\end{array}$ \\
\hline $\begin{array}{l}\text { Secondary Use / } \\
\text { Study Conducted using } \\
\text { Observational Routinely-collected } \\
\text { health Data }\end{array}$ & $\begin{array}{l}\text { RECORD / STROSA } \\
{[12,13]}\end{array}$ & $\begin{array}{l}\text { https://www.record-statement.org// } \\
\text { https://doi.org/10.1055/s-0042-108647 }\end{array}$ \\
\hline Evaluation study of Healthcare IT & STARE-HI [7] & $\begin{array}{l}\text { https://imia-medinfo.org/wp/wp- } \\
\text { content/uploads/2016/09/Stare- } \\
\text { HI_as_published.pdf }\end{array}$ \\
\hline Survey & $\begin{array}{l}\text { Report Standard for } \\
\text { Surveys [14] }\end{array}$ & https://doi.org/10.1093/intqhe/mzg031 \\
\hline Systematic Review & PRISMA [15] & $\begin{array}{l}\text { https://www.equator- } \\
\text { network.org/reporting- } \\
\text { guidelines/prisma/ }\end{array}$ \\
\hline Scoping Review & Instruction for Authors & $\begin{array}{l}\text { https://www.gmds.de/fileadmin/user_up } \\
\text { load/Publikationen/01a_autorenhinweise } \\
\text { fuer_scoping_reviews.pdf [16] }\end{array}$ \\
\hline $\begin{array}{l}\text { Technical Case Report / Lessons } \\
\text { Learned }\end{array}$ & Instruction for Authors & $\begin{array}{l}\text { https://www.gmds.de/fileadmin/user_up } \\
\text { load/Publikationen/01b_autorenhinweise } \\
\text { fuer technical case report.pdf [17] }\end{array}$ \\
\hline
\end{tabular}


The submission should correspond to the International Committee of Medical Journal Editors (ICMJE) 'Uniform Requirements' [5] or the Reporting Standards of the Equator Network [6]. Most submissions are structured according to IMRD: Introduction, Methods, Results, Discussion. For studies evaluating healthcare IT Study Context is added after Introduction in accordance with STARE-HI [7]. Technical and Case Reports are structured according to ISCIL (Introduction, State of the Art, Concept, Implementation, Lessons Learned). For deviating standards, especially for technical contributions from (medical) informatics, please refer to the table below. The specific requirements for publication in Studies in Health Technology and Informatics or GMS MIBE must be followed carefully. All submissions of contributions are made available via the online registry set up for the respective conference.

\section{How to find the right strategies for publications?}

\subsection{Scientific value}

Publications as an indicator of scientific output are evaluated quantitatively and qualitatively in research according to the publishing journal's importance (ImpactFactor). Universities often prefer journal papers and incentivize them, e.g., via 'performancebased funding' for the authors' institutes. These evaluations can be regarded critically [18], but they are also frequently used, especially in grading and acceptance of theses based on publications at universities.

However, most universities accept IOS full papers submitted to conferences as part of PhD work. The Studies in Health Technology and Informatics series is an esteemed and widely used series, which, guarantees a peer-review process with the publication and an international reputation through the English language. Studies in Health Technology and Informatics is indexed in MEDLINE/PubMed among others, but unlike journals it has no impact. Submitting to a conference can conflict with submitting to a journal, but certain publication strategies balance both and create a symbiotic co-existence.

\subsection{Influencing factors}

There are various factors that influence the decision whether to publish in a conference proceeding or in a scientific journal. In order to simplify the decision slightly, we have developed a scheme based on the most common factors and the personal experiences of the authors in order to choose the right type of publication. The decision can be supported by answering the following questions (see figure 3):

Is your scientific work indicated as preliminary results or minor aspects of the project? If yes, submit an abstract to GMDS annual conference other platforms may consider the content not sufficiently relevant. Otherwise, think about whether you already published on the topic. If yes, submit an abstract to GMDS. If no, ask yourself whether publication needs some more time pressure. As this is almost always the case, the next thing to check is whether a journal publication is still missing for e.g. a PhD. If yes, choose a scientific journal having a focus on your topic, then write a manuscript according to the respective instructions for authors. Otherwise, write a full paper to either MIBE (German or English with more national focus) or Studies in Health Technology and Informatics (English with more international focus). 


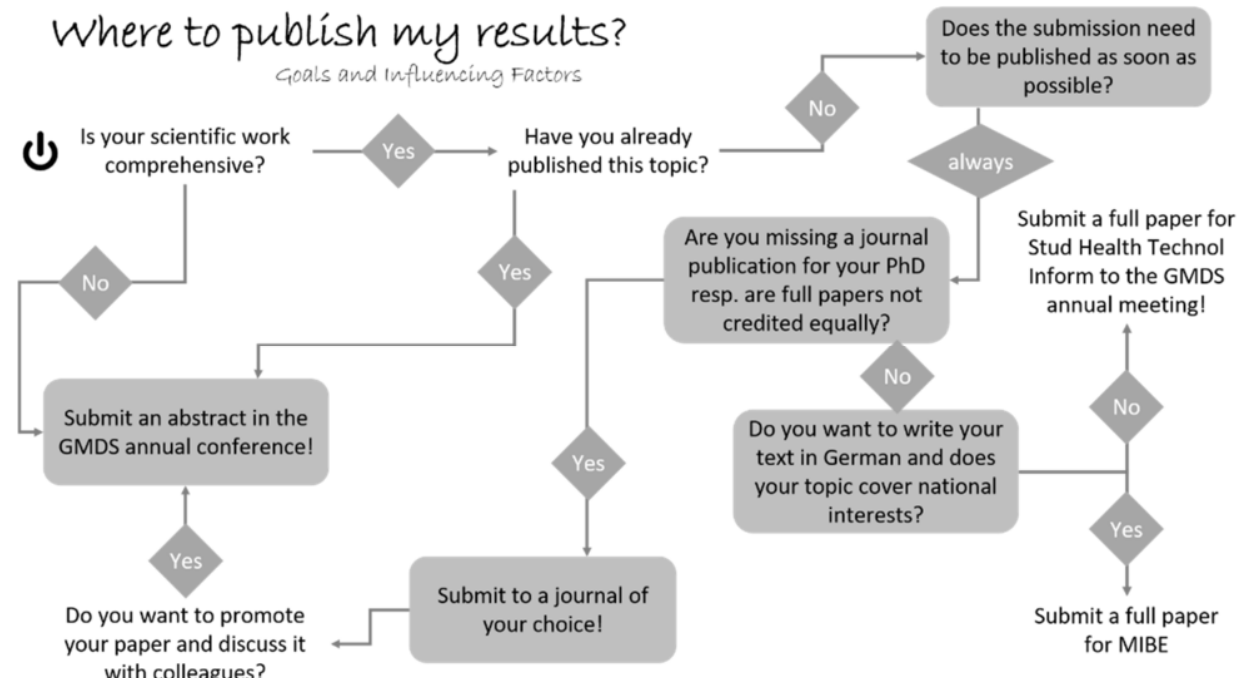

Figure 3: Exaggerated and simplified decision tree to publication.

\subsection{Conclusion}

This editorial provides examples for basic differences, pros and cons, and guides in choosing the right submission type and target. The wide range of journals and conferences can be difficult to overview without an in-depth insight and cannot be covered by this editorial. We consider this editorial as a guide to publication for GMDS annual meetings . Based on personal experiences we want to give recommendations to young scientists which proceeding to choose. Future scientists should be more aware of their impact on society and politics and publish the results of their work through the right channels. This is why it is so difficult to select the right publication, especially given the pressure from the university to publish in listed journals with a high impact factor.

\section{References}

1. Deutsche Gesellschaft für Medizinische Informatik, Biometrie und Epidemiologie GMDS e. V. [Internet]. GMDS e. V. [cited 25. März 2021]. Available from: https://www.gmds.de

2. Röhrig R, Hübner U, Sedlmayr M. German Medical Data Sciences in Studies in Health Technology and Informatics - Reflections on the 5th Volume. 2021. TBD

3. GMS | Homepage [Internet]. [cited 31. März 2021]. Available from: https://www.egms.de/dynamic/ en/index.htm

4. GMS | GMS Medizinische Informatik, Biometrie und Epidemiologie | Für Autoren [Internet]. [cited 31. März 2021]. Available from: https://www.egms.de/static/de/journals/mibe/authors.htm

5. ICMJE $\mid$ About ICMJE $\mid$ ICMJE Recommendations (,The Uniform Requirements“) [Internet]. [cited 6. April 2021]. Available from: http:/www.icmje.org/about-icmje/faqs/icmje-recommendations/

6. Reporting guidelines | The EQUATOR Network [Internet]. [cited 6. April 2021]. Available from: https://www.equator-network.org/reporting-guidelines/

7. Talmon J, Ammenwerth E, Brender J, de Keizer N, Nykänen P, Rigby M. STARE-HI--Statement on reporting of evaluation studies in Health Informatics. Int J Med Inform. 2009;78(1):1-9.

8. Schulz KF, Altman DG, Moher D, for the CONSORT Group. CONSORT 2010 Statement: updated guidelines for reporting parallel group randomised trials. Ann Int Med. 2010;152(11):726-32. DOI: 10.7326/0003-4819-152-11-201006010-00232. 
9. von Elm E, Altman DG, Egger M, Pocock SJ, Gotzsche PC, Vandenbroucke JP. The Strengthening the Reporting of Observational Studies in Epidemiology (STROBE) Statement: guidelines for reporting observational studies. Ann Intern Med. 2007; 147(8):573-577. DOI: 10.7326/0003-4819-147-8200710160-00010.

10. Bossuyt PM, Reitsma JB, Bruns DE, Gatsonis CA, Glasziou PP, Irwig L, LijmerJG Moher D, Rennie D, de Vet HCW, Kressel HY, Rifai N, Golub RM, Altman DG, Hooft L, Korevaar DA, Cohen JF, For the STARD Group. STARD 2015: An Updated List of Essential Items for Reporting Diagnostic Accuracy Studies. BMJ. 2015;351:h5527. DOI: 10.1136/bmj.h5527.

11. Ogrinc G, Davies L, Goodman D, Batalden P, Davidoff F, Stevens D. SQUIRE 2.0 (Standards for QUality Improvement Reporting Excellence): revised publication guidelines from a detailed consensus process. BMJ Qual Saf. 2015. DOI: 10.1136/bmjqs-2015-004411.

12. Benchimol EI, Smeeth L, Guttmann A, Harron K, Moher D, et al. (2015) The REporting of studies Conducted using Observational Routinely-collected health Data (RECORD) Statement. PLOS Medicine 12(10): e1001885. https://doi.org/10.1371/journal.pmed.1001885.

13. Swart E, Schmitt J. STandardized Reporting Of Secondary data Analyses (STROSA) - A recommendation. Zeitschrift für Evidenz, Fortbildung und Qualität im Gesundheitswesen. 108(8): 511516. DOI: 10.1016/j.zefq.2014.08.022.

14. Kelley K, Clark B, Brown V, Sitzia J. Good practice in the conduct and reporting of survey research, International Journal for Quality in Health Care, 2003. 15(3):261-266 DOI: 10.1093/intqhc/mzg031

15. Page MJ, McKenzie JE, Bossuyt PM, Boutron I, Hoffmann TC, Mulrow CD, Shamseer L, Tetzlaff JM, Akl EA, Brennan SE, Chou R, Glanville J, Grimshaw JM, Hróbjartsson A, Lalu MM, Li T, Loder EW, Mayo-Wilson E, McDonald S, McGuinness LA, Stewart LA, Thomas J, Tricco AC, Welch VA, Whiting P, Moher D. The PRISMA 2020 statement: An updated guideline for reporting systematic reviews. PLoS Med. 2021;18(3):e1003583. DOI: 10.1371/journal.pmed.1003583

16. von Elm E, Schreiber G, Haupt CC. Methodische Anleitung für Scoping Reviews (JBI-Methodologie). 2019. 143: 1-7. DOI: 10.1016/j.zefq.2019.05.004.

17. Röhrig R, Sedlmayr M. Autorenhinweise Technical Case Report [Internet]. [cited 6. April 2021]. Available from: https:/www.gmds.de/fileadmin/user_upload/Publikationen/01b_autorenhinweise_fuer technical_case_report.pdf

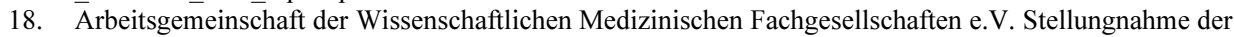
AWMF zur Evaluation der medizinischen Forschungsleistung. Juli 2014;2. 